\title{
EdUCAÇÃO E ESCOLA NO MEIO RURAL DE LONDRINA EM TRAÇOS HISTÓRICO-SOCIOLÓGICOS
}

\author{
Maria Regina Clivati Capelo \\ Professora do Departamento de Ciências Sociais \\ da Universidade Estadual de Londrina.
}

E-mail: capelo@sercomtel.com.br

\section{Resumo}

\begin{abstract}
Registrar em perspectiva histórico-sociológica traços da dinâmica cultural que possibilitaram a estruturação do sistema escolar rural londrinense constitui o propósito mais imediato deste artigo. Visualizando a escolarização rural através do fio condutor da diversidade sociocultural, foi possível revelar a presença da educação jesuítica na região onde se formou o município de Londrina, bem como outras experiências escolares de características étnicas que representavam a modernidade laica e burguesa. Esse olhar, um entre tantos possíveis, permite focalizar a complexidade dos processos educativos.
\end{abstract}

Palavras-chave: escolarização rural; diversidade sociocultural; dinâmica cultural.

\section{Introdução}

s momentos mais definidos da escolarização rural podem ser divididos da seguinte forma: antes de 1930, quando o território em que se formou Londrina era ocupado por índios, caboclos e uns poucos negros. Esse período remonta ao século XVII, tempo das missões e escolas de "civilização" fundadas por jesuítas.

Durante os anos de 1930, etapa em que se efetiva a reocupação capitalista do território onde Londrina está localizada, foram criadas as primeiras escolas rurais fundadas por imigrantes europeus e japoneses. É o tempo das escolas de processos étnicos. 
Depois de 1940, especialmente após a Segunda Guerra, acontece o processo de nacionalização e fechamento das escolas estrangeiras. Nesse período emerge um sistema de ensino rural com características municipais, isto é, com as marcas do nacionalismo de Vargas.

Essa última fase coincide, em parte, com o auge da cafeicultura londrinense, ocorrido entre 1950 e 1970 , momento de expansão das escolas rurais isoladas. Desde então, a escolarização rural passa a experimentar uma nova etapa de organização em face do constante êxodo rural provocado pelo aprofundamento do capitalismo no campo.

Trata-se de uma periodização que permite revelar aspectos que estavam ocultos por trás de uma história educacional homogênea e harmônic, que permite, ainda, visualizar o fenômeno educativo como parte componente do avanço do capitalismo, como peça fundamental do processo civilizador empreendido pelo capital em regiões que, até as primeiras décadas dos anos 1900, eram habitadas principalmente por índios.

\section{Escolas jesuíticas: etapa primeira da escolarização}

Desde o séc. XVII, conforme o Padre Ruiz de Montoya (1985), havia reduções indígenas nos sertões do Tibagi, rio que atualmente margeia a parte leste do município de Londrina. Nelas os jesuítas fundaram escolas de "ler e escrever" e tratavam de "civilizar os selvagens", cristianizando-os. Essas reduções foram alvo dos ataques dos bandeirantes, entre 1628 e 1632 . Depois, o território foi abandonado e, pouco a pouco, reapropriado por índios kaingáng que viviam mais a leste, no interior das matas, afastados dos ataques predatórios dos bandeirantes.

Durante os séculos XVIII e XIX, as potencialidades da região foram reconhecidas através de expedições nacionais e estrangeiras que, obviamente, não podem ser consideradas apenas como estratégias passageiras de reconhecimento dos sertões. Ao longo de muitos trajetos, as expedições iam deixando homens e, como ensina Darci Ribeiro, "mulheres índias ou negras prenhas". Os bandeirantes fixavam homens que permaneciam em clareiras abertas nas matas para marcar 
posses portuguesas além dos limites traçados pelo Tratado de Tordesilhas. Registros de viajantes (Bigg-Whiter, 1974; Saint-Hilaire, 1964) que integraram expedições de reconhecimento dos sertões na região, dão conta da existência de índios, negros e caboclos.

A partir de 1850, novas tentativas de ocupação dos sertões do norte do estado do Paraná resultaram na instalação da Colônia Militar de Jataí e do aldeamento de São Pedro de Alcântara onde viviam escravos/negros, índios e os brancos que governavam as relações sociais : o padre, o administrador, o mestre-escola, funcionários, entre outros. Das escolas existentes nesse período, pode-se conhecer apenas alguns traços que constam em relatos de viajantes. As informações são esparsas e muitas vezes imprecisas, mas, segundo consta em Boutin (1979, p.63), havia um diretor no aldeamento cuja esposa criou uma escola feminina que funcionava com 13 alunas, sendo que o mesmo número de meninos frequientava a escola masculina. Em ambas, os indígenas eram batizados, sinalizando uma forma de submissão aos rituais dos brancos.

Conforme Boutin (1977, p.25), na Colônia Militar, a escola foi criada em 1870 mas as aulas para moças começaram a ser ministradas somente em 1884, pois era inconcebível a presença de ambos os sexos na mesma sala de aula. Em 1877, havia no aldeamento de São Jerônimo,

"um professor de música e uma professora de primeiras letras. O professor recebia a gratificação anual de seiscentos mil réis e ela setecentos e vinte réis. Não sabemos a razão dessa diferença de salário. (Boutin, 1979, p.72).

Escolas e igrejas se reproduzem no meio rural acompanhando o avanço do capitalismo e vão servindo, ao mesmo tempo, para redefinir as temporalidades e espacialidades. Assim, a história oficial passou a ser contada através do etnocentrismo dos colonizadores brancos, os "pioneiros" da modernidade. Portanto, a fixação desse marco histórico implicou, de um lado, a notabilização e visibilidade social dos "de fora" que vieram para reocupar as terras e, de outro, a exclusão do universo social pré-existente. Dentro desse universo ficou esquecida a experiência escolar jesuítica do século XVII e a educação catequética realizada sob orientação dos padres capuchinhos, 
no século XIX, que também foi encoberta, silenciada. Índios, caboclos e negros que de fato eram os de "dentro", foram desalojados, tornando-se os de "fora".

A criação do SPI (Serviço de Proteção ao Índio) em 1910, que se transformou no Serviço de Proteção e Localização dos Trabalhadores Nacionais (e mais tarde também a criação da FUNAI), facilitou o desenvolvimento de políticas "assistencialistas e "integracionistas" de índios e caboclos. Tratava-se de incluir a "educação" como um serviço que facultaria o progresso moral, intelectual e prático de índios e caboclos para que se integrassem de modo subalterno no mercado de trabalho. No lugar da educação catequética punha-se uma escola fundamentada nos princípios do positivismo e garantida pela "proteção militar". Nos anos 40, ressurgem propostas educacionais baseadas na mesma lógica do trabalho desenvolvido pelo SPI, mas acrescidas de fundamentos raciais.

Vários foram os planos para tentar incorporar o caboclo na "civilização nacional", especialmente no Paraná, ainda nos anos 40, quando a diversidade de imigrantes poderia resultar na presença de grupos sociais "indesejados" ou "exóticos". Diante dessa possibilidade, para as elites dominantes era mais adequado investir na educação do caboclo. A alfabetização era somente uma parte da tarefa a ser empreendida, no sentido de "civilizar" ou moralizar o caboclo, pois, mesmo iniciado nas primeiras letras, permanecia apático, o que significa dizer que não se deixava "civilizar" ou "integrar-se" facilmente.

\section{Diversidade étnica em contexto capitalista}

As primeiras escolas, em contexto capitalista, na região de Londrina, foram criadas por imigrantes estrangeiros, especialmente europeus e japoneses que, na condição de adventícios compunham "colônias" rurais homogêneas ou mistas. Tão logo as terras estivessem cercadas, fundavam escolas e igrejas, verdadeiras mediações que anunciavam o advento da civilização numa região cujos habitantes índios, caboclos e uns poucos negros - além de rarefeitos, possuíam outros modos de vida que não se coadunavam com o capitalismo. 
Na década de 1930 predominaram as iniciativas escolares organizadas nas colônias de estrangeiros e também por migrantes nacionais, especialmente paulistas e mineiros. Entre as escolas européias ${ }^{1}$ destacam-se a alemã, a polonesa e a dos eslovacos. Elas eram concebidas e concretizadas segundo um modelo definido, apresentando similaridades no tocante às práticas pedagógicas e à organização escolar que reproduzia, em território sertanejo, o modelo ocidental, cristão, masculino e branco. Eram espécies de aparatos civilizatórios e modernizantes.

A religiosidade estava presente nas escolas de origem européia. Não raro, a própria escola transformava-se no "templo" sagrado abrigando as missas católicas ou cultos luteranos, bem como festas, bailes e outras manifestações esportivas e culturais promovidas pelos grupos étnicos que almejavam construir, através da escola, suas visibilidades na sociedade envolvente. Apesar das diferenças e especificidades entre as experiências escolares européias (a alemã era mais homogênea, a eslovaca heterogênea ${ }^{2}$ e a polonesa estava integrada à sociedade envolvente, isto é, era mais brasileira), elas tinham em comum o fato de serem iniciativas comunitárias que supriam a ausência do poder público no campo educacional. Ao mesmo tempo, almejavam transmitir as tradições étnicoculturais através do ensino em língua de origem. Mas, assim organizadas, tiveram uma existência efêmera, especialmente se comparadas com as estratégias utilizadas pelos japoneses, a fim de garantir espaço para a transmissão das tradições e valores nipônicos. As escolas japonesas de colônias rurais eram diferentes do modelo europeu.

Os japoneses desenvolveram, em território sertanejo, outras estratégias de preservação das tradições culturais, a começar pelo modo como se organizaram nas colônias, criando associações e entidades representativas. Em cada colônia ou seção a escola se confun-

1 Conforme dados do Departamento Nacional do Café (DNC), em 1941, os italianos formaram o segundo grupo étnico mais denso de trabalhadores na cafeicultura londrinense. Eram 3.404 de um montante de 10.980 estrangeiros. Geralmente reinigrados do estado de São Paulo, não se congregaram em colônias muito coesas. Os professores entrevistados referem-se ao fato de que davam aulas em escolas onde havia muitos italianos, por isto, as crianças falavam com sotaque.

2 A Colônia Bratislava foi constituída na década de 1930. Era composta por, mais ou menos, 40 famílias de origem eslovaca, 13 portuguesas, 11 italianas, 6 alenãs, 4 húngaras, 2 espanholas e 6 brasileiras. 
dia com o clube escolar no qual eram planejadas e concretizadas todas as atividades de lazer e as competições poliesportivas. Eram escolas que, do ponto de vista cultural, tentavam recriar o Japão no sertão norte paranaense. O clube estava, ao mesmo tempo, dentro e fora da escola. Por isto não podia ser aprisionado pelos controles burocráticos. Esta é a diferença básica entre o modelo europeu e o modelo japonês, já que este é inseparável do clube cultural e totalmente separado da igreja, ao passo que o modelo europeu leva a igreja para dentro da escola.

$\mathrm{O}$ advento da Segunda Guerra Mundial implicou o fechamento dessas escolas e de outras que também desenvolviam processos étnicos. Inicia-se, então, uma outra fase da educação local, na qual se nota a presença do poder público municipal, controlando e organizando as atividades escolares. A municipalização das escolas estrangeiras vai ocorrendo concomitantemente com o desenvolvimento das políticas de nacionalização.

Todas as escolas rurais passaram por uma espécie de homogeneização refletida na obrigatoriedade do ensino em língua pátria e nos conteúdos programáticos. Não se tratava apenas de nacionalizar o estrangeiro, mas também, de assimilar de modo periférico os grupos sociais inclusivos (índios, negros e caboclos) que resistiam ao modelo de sociedade e de produção da vida.

\section{Dos anos 1950 a 1970: a escola rural no tempo do café.}

No período posterior a 1950 , a cafeicultura apresenta as melhores chances de progresso e as demandas por escolas rurais crescem, refluindo nos anos 70, quando a cafeicultura passa a experimentar uma fase de declínio. Pode-se falar num sistema escolar rural organizado sob os auspícios do município desde o final de 1940, momento em que as escolas estrangeiras já estavam nacionalizadas. É necessário destacar que, nos primeiros tempos de modernização capitalista, paulistas e mineiros muito contribuíram para a consolidação do sistema escolar rural; via de regra, foram os primeiros professores. 
Todo o processo de reocupação das terras situadas ao norte do estado do Paraná foi predatório do meio ambiente e baseado na exploração do trabalho familiar. Os próprios trabalhadores pagavam com cafezal o direito de usar as terras na produção de alimentos. Em 1940, de acordo com dados do cadastro de estabelecimentos rurais do Paraná (IBGE, 1941) havia em Londrina 21.819 trabalhadores rurais. Desses, 13.235 eram mulheres e menores, sendo que os homens adultos somavam 8.584. Nessas condições, a escolarização de crianças ficava em planos bastante secundários, diante da intensidade com que se utilizava a mão-de-obra infantil na cafeicultura. Isso não significava que os trabalhadores rurais desvalorizassem a escola, ao contrário, a escola representava, para eles, a possibilidade de apropriação dos saberes necessários à integração com o mundo urbano.

A distribuição das escolas rurais foi se configurando ao largo da expansão dos cercamentos, isto é, seguindo os caminhos traçados pela reocupação das terras. Onde era instalada uma serraria, formava-se um povoado ou um bairro rural. Entre os anos 50 e 60, a instalação de escolas nas fazendas passou a ser, por vezes, uma exigência dos proprietários. Os locais escolhidos para a construção das escolas isoladas eram definidos pela quantidade de crianças que necessitavam estudar. Com a criação do Departamento de Educação Pública e Assistência Social -DEPAS - em 1949, são delineados alguns traços mais definidos de uma política de educação municipal, alinhada ao nacionalismo-modernista que prevalecia no plano político mais amplo. O DEPAS centralizou as decisões sobre educação rural como forma de controlar os professores que ficavam isolados nas escolas de fazendas e como um meio de tentar qualificar, em serviço, um professorado praticamente leigo. A qualidade docente requerida estava relacionada com a produção das condições adequadas para a concretização do nacionalismo brasileiro, em cada escola.

Nos anos 50, observa-se toda sorte de minuciosas instruções nas circulares que eram enviadas aos professores. Elas incluíam desde elogios aos docentes que conseguiam obter $50 \%{ }^{3}$ ou mais de aprova-

\footnotetext{
${ }^{3}$ Esse percentual está registrado na carta circular enviada pelo departamento de Educação Pública e Assistência Social, em julho de 1953, aos professores rurais de Londrina, na qual eram instruídos sobre a melhor maneira de ensinar.
} 
ção nos exames finais até a divulgação pública, como represália, dos nomes das escolas, cujos mestres não haviam tomado as providências exigidas pelo Departamento. Na verdade, tratava-se de escolas altamente seletivas, com exames finais obrigatórios", aplicados por "bancas examinadoras", normalmente compostas por professores da cidade, desconhecidos dos alunos. Os formalismos, a ritualização e a alta seletividade que caracterizavam a realização dos exames finais sugeriam, simbolicamente, para as crianças rurais, que a carência de competências cognitivas as impedia de atuar em campos mais exigentes do mundo do trabalho. De outro lado, retratava as dificuldades que permeavam a aquisição dos conhecimentos escolares, num período em que ser portador de um mínimo desses saberes significava ascender a um status social mais elevado, significava distinguir-se do que era comum. Para a grande maioria das crianças rurais, as oportunidades de acesso e permanência ficavam limitadas pelo modo como a escola estava organizada e pelos meios excludentes de que lançava mão.

\section{Considerações Finais}

Ao focalizar prioritariamente a historia da educação local a partir das iniciativas dos imigrantes europeus e japoneses, após os anos 1930, a historiografia ajuda a tornar invisíveis as experiências educativas e escolares desenvolvidas pelos jesuítas na região norte do Estado do Paraná, especialmente ao longo do rio Tibagi. Tratava-se de um território ocupado por índios, negros e caboclos que foram desalojados por meio de expedientes expropriatórios utilizados pelos imigrantes e migrantes. Registrar essa parte da história, ainda que em fragmentos, significa recuperar um passado que estava destinado ao esquecimen-

\footnotetext{
${ }^{4}$ Atas de exames arquivadas na Secretaria Municipal de Educação permitem verificar em dados quantitativos a seletividade nas escolas rurais. Por exemplo: nos exames de 1953, numa dada escola rural, dos 29 alunos da primeira série, apenas 4 foram aprovados, 22 não compareceram aos exames e os demais foram reprovados. A seletividade concentrava-se, à primeira vista, na série inicial. As exigências e a rigidez dos exames também implicava o abandono dos estudos pois eram ocasiões muito temidas por parte dos alunos.
} 
to. Um passado que era retratado como harmônico e no entanto se mostra complexo e diverso.

Obviamente não há como ignorar que a modernidade educacional, representada pela escola laica, burguesa, nacional (com características européias), é inaugurada a partir das práticas desenvolvidas pelos imigrantes que chegavam à região, desde 1930, como portadores de saberes e fazeres desconhecidos pela rarefeita população préexistente, cujas necessidades educacionais eram satisfeitas no cotidiano vivido.

Em contraste com o modo de vida que predominava nos sertões localizados no norte (assim chamado novo) do Paraná, a derrubada intensa das matas, com os cercamentos das terras, a edificação de escolas e igrejas, significava a introdução do estilo de vida "civilizado" que ora se impunha pelo avanço das forças históricas modernizantes. Assim, os imigrantes (europeus e japoneses) representavam a modernidade, enquanto o modo de vida dos caboclos, índios, negros e até mesmo de certos fazendeiros préexistentes, significava o atraso.

Tomar a diversidade cultural como fio condutor da análise possibilita entender que, mediando a dialética atraso/modernidade, a educação escolar aparece como o elemento capaz de apagar o atraso, introjetando, nos sujeitos "aborígenes" a racionalidade adequada ao mercado nascente. Os projetos de transformação dos índios e caboclos em "trabalhadores rurais" apostavam nessa perspectiva, pois, ainda que propusessem a integração, tratava-se de um integração subalterna, uma inclusão excludente.

A diversidade étnica persistiu até o florescimento dos ímpetos nacionalistas que, em 1950, implicaram uma espécie de homogeneização das experiências escolares. A criação do Departamento de Educação Pública e Assistência Social coincidiu com a política de nacionalização. Desde então, toda a sorte de mecanismos próprios do centralismo burocrático foram desenvolvidos no sentido de assegurar a concretização de uma educação nacional. O nacional, neste caso, era mais o estrangeiro, isto é, o de "fora" que se tornou de "dentro", enquanto os que realmente eram de "dentro" foram desalojados e relegados ao esquecimento. 


\section{Referências Bibliográficas}

BOUTIN, Leônidas. Colônias Indígenas na Província do Paraná. Boletim do Instituto Histórico. Geográfico e Etnográfico Paranaense, Curitiba, v. 36, p.49-75, 1979 .

Colônia Militar do Jatahy. Boletim do Instituto Histórico, Geográfico e Etnográfico Paranaense. Curitiba, v. 33, p. 13-27, 1977.

COLÔNIA Militar do Jatahy. Boletim do Instituto Histórico, Geográfico e Etnográfico Paranaense, Curitiba, v. 33, p. 13-27, 1977.

INSTITUTO BRASILEIRO DE GEOGRAFIA E ESTATÍSTICA. Departamento Nacional do Café. Atlas Corográfico da Cultura Cafeeira - Estado do Paraná. Rio de Janeiro : Pimenta de Mello e Cia, 1941.

MONTOYA, A. Ruiz de. A Conquista Espiritual : Feita pelos religiosos da Companhia de Jesus nas Provincias do Paraguai, Paraná, Uruguai e Tape. Porto Alegre : Martins Livreiro, 1985.

\section{Abstract}

The main goal of this work is to register, in a historico-sociological perspective, traces of the cultural dynamics that allowed the structuralization of Londrina's rural school system. Using the socio-cultural diversity as the leading thought, it was possible to visualize the process of the rural school installment, revealing the Jesuitic education presence in the region of Londrina and, other school experiences of ethnic characteristics that represented the laical and bourgeois modernity. This particular view, among so many possibilities, allows focusing on the complexity of educational processes.

Key-words : rural school; cultural diversity; cultural dynamics. 